\title{
Um ensaio sobre a organização de repositórios públicos e o subsídio do fazer científico
}

\section{An essay on the organization of public repositories and the support to the scientific practice}

\section{Rodrigo Piquet Saboia de Mello \\ Doutor e Mestre em Ciência da Informação pelo Instituto Brasileiro de Informação em Ciência e Tecnologia (IBICT). Chefe do Núcleo de Informação Científica do Museu do Índio/ Fundação Nacional do Índio (FUNAI)}

rodrigopiquetuff@hotmail.com

Recebido em: 14/02/2020

Aceito em: 23/05/2020

\section{Introdução}

O presente ensaio traz algumas questões atinentes a cientistas e pesquisadores em geral sobre os espaços de estudo, organização e classificação do conhecimento em repositórios públicos.

Minha experiência à frente de acervos no Museu do Índio, instituição técnica-científica da Fundação Nacional do Índio (FUNAI), nos últimos anos me permite tecer algumas reflexões no âmbito da organização do conhecimento, sua classificação e disseminação de informações.

Desde já, é importante aventar que na formação de coleções são imperiosos alguns questionamentos basilares neste campo do conhecimento, tais como: o quê, o porquê, o para quê, o como e o para quem colecionar (WEITZEL, 2002, 2012). Assim sendo, desde o aprendiz de feiticeiro da ciência até o pesquisador maduro com anos de estrada, o norte da constituição e organização de um repositório público é a finalidade da existência.

O ensaio acadêmico como gênero textual é por definição uma exposição de ideias do autor com foco na originalidade, uma quase divagação de quem detém algum percurso profissional e/ ou acadêmico. Porém, como tenho adscrito em minha pessoa um perfil diria organizacional, a presente elaboração seguirá este roteiro: serão discutidos os intitulados espaços privilegiados de produção acadêmica, em seguida será abordada a organização e classificação do conhecimento e, por fim, algumas reflexões que venham provocar nos leitores futuras escritas, meditações ou refutações. 


\section{Os espaços privilegiados de produção intelectual?}

Aqui intitulados como espaços privilegiados de produção intelectual como arquivos, museus e, em especial, bibliotecas se constituem os alicerces tradicionais do labutar científico. Porém, não basta a construção de um espaço de estudo e conhecimento, mas uma relação de sociabilidade em que os agentes envolvidos no processo científico estejam numa constância dinâmica de fazer e agir. Neste mesmo diapasão:

Esta condição se estabeleceu a partir das configurações sociotécnicas que emergiram nas últimas décadas do século XX, marcadas, principalmente, pelas tecnologias, mas, também, pela condição de vida e trabalho da sociedade na atualidade, pautada na flexibilidade, rapidez e eficiência nos processos organizacionais. Diante desse panorama, estas instituições, assim como os profissionais que atuam nesses espaços, são convocadas ao diálogo, de um lado com as práticas de sociabilidade que surgem a partir dessas novas configurações sociotécnicas e, de outro lado, com as práticas, chamadas "tradicionais", vigentes nas instâncias da vida social. (MACHADO; ELIAS JUNIOR, ACHILLES, 2014, p. 115)

Uma consideração que reputo fundamental na hodiernidade é o fomento que as tecnologias de informação e comunicação (TICs) tiveram nas últimas décadas. Antes espaços privilegiados de conhecimento e saber, unidades de informação como bibliotecas foram rivalizadas por aparatos eletrônicos portáteis que podem trazer grandes bibliotecas à mão de qualquer consulente. A partir da sentença, fica a provocação: até que ponto a biblioteca ainda é um espaço privilegiado de produção e disseminação intelectual?

Hoje é possível inclusive questionar a própria academia como o local de criação e disseminação do conhecimento dito qualificado. Com a emergência de etnosaberes e outros conhecimentos não baseados no método científico, são abertos pontes e canais ímpares para um novo modelo societário de como executar novos paradigmas que venham melhorar a vida em sociedade.

De todo modo, cabe problematizar que os locais de produção do conhecimento pelos etnosaberes ou pelo fazer científico detêm em seu âmago regras e métodos próprios. Ou seja, não se perfazem como construções excludentes, mas sim complementares da sabedoria humana.

Nesta ação orientada democraticamente da produção do conhecimento, o fomento dos movimentos associativos, de bairro e até sindicais podem sinalizar para a construção de alicerces de conhecimento e informação para a sociedade civil. Um bom exemplo são as bibliotecas comunitárias em que o próprio tecido social local estabelece práticas para a constituição de organização e disponibilização dos acervos eleitos como relevantes para o grupo (PRADO, 2010).

Nesse modo comunitário de certo tipo de produção intelectual, as sociedades das mais diversas origens e estruturas geram espaços privilegiados para a constituição de locais ou fazeres do conhecimento. Das religiões de origem africana passando pelos saberes sertanejos e populares, grupos sociais dos mais diversos matizes geram estruturas de saber, sedimentadas ou não em instituições ou somente tão poderosas quanto a oralidade disposta pela ancestralidade.

Em minha trajetória como gestor de acervos indigenistas conjugada a reflexões de natureza acadêmica, observei e refleti sobre o empoderamento dos povos indígenas na constituição de acervos e como este ato político representou uma importante mudança epistêmica para estes grupos. Desta maneira:

Se antes os povos indígenas eram dependentes do conhecimento dos agentes do Estado para os registros das suas manifestações culturais, na atualidade os próprios indígenas começaram a se qualificar para realizar ações de salvaguarda dos aspectos culturais étnicos a partir de ações informacionais, além de permitir novos desdobramentos documentários para atender as crescentes demandas de informações por esses povos. (MELLO, 2019, p. 22) 
Para pontuar, esmiuçar como cada povo indígena promoveu sua ação informacional seria inviável, visto a profunda diversidade étnica, linguística e cultural desses grupos. O que seria passível de reflexão são conjunturas específicas de aprofundamento informacional (e democrático) do empoderamento dos povos indígenas quando, por exemplo, lideranças indígenas se tornaram proa de movimentos políticos por autonomia e autossuficiência.

Portanto, a ação estatal descolada das demandas informacionais de povos ditos periféricos, como povos indígenas, foram pouco a pouco fagocitados na constituição de inovadoras maneiras de organização política e informacional. Assim como povos indígenas se tornaram líderes de um processo informacional, demais grupos devem se apropriar para criar novas elaborações organizacionais e identitárias. Este tipo de ação direcionado de empoderamento de grupos alijados do centro decisório de poder recebeu o epíteto de luta documentária (MELLO, 2018).

\section{A organização e classificação do conhecimento como subsídio para a atuação científica}

Pensar em organização e classificação do conhecimento para a iniciativa científica é refletir sobre um cabedal de dispositivos informacionais que venham proporcionar uma mais eficaz recuperação do conhecimento. Os profissionais da informação como bibliotecários, arquivistas e museólogos, com seus instrumentos de trabalho podem proporcionar, aliados aos cientistas, uma gama de ferramentas de apoio ao fazer científico.

Um aspecto inicial que merece ser refletido é que não existe uma dada organização ou classificação mais correta. Na verdade, dependendo do contexto da produção intelectual ou descoberta científica, uma dada classificação de um acervo pode atender melhor a um grupo de pesquisa em comparação a outro. Neste sentido:

[...] é óbvio que podemos ter muitas classificações. Não existem portanto nenhuma razão em julgar qualquer classificação como sendo certa ou errada. Ela pode ser apenas mais ou menos adequada para o seu propósito, embora algumas classificações possam servir a mais propósitos do que outras. (LANGRIDGE, 1977, p. 17)

Destarte, um posicionamento mais relativista da organização de acervos científicos é salutar, por mais que os instrumentos documentários estejam à disposição para um enquadramento mais racional ou prático das coleções das instituições. Claro que cada profissional da informação detém seu cabedal de conhecimentos com o fito de organizar coleções. Porém, a atenção ao consulente dos acervos deverá ser o norte na constituição do material a ser colecionado e posto à disposição da comunidade científica ou da sociedade em geral.

A própria construção de um instrumento documentário, como um vocabulário controlado ou um tesauro, detém uma finalidade específica. Ou seja, um tesauro sobre História Antiga elaborada para pesquisadores de pós-graduação pode não ter a mesma serventia a religiosos em um mosteiro. Assim, cabe aos grupos produtores de conhecimento elaborarem seus próprios instrumentos criando múltiplas possibilidades. Ainda neste sentido:

Há tantas possibilidades de classificar quantas forem as semelhanças e diferenças existentes entre os objetos ou as ideias a classificar. [...]. Existem tantas classificações quantas forem as características possíveis de serem empregadas como base da divisão. (PIEDADE, 1977, p. 14)

A passagem acima ilustra bem a diversidade da natureza do processo classificatório. A ação classificacionista é múltipla e de importância para a atuação científica. Assim, pesquisadores podem ter em suas mãos as informações necessárias de maneira célere, visto a organização disposta e classificada de um dado acervo. 
Outra reflexão sobre a organização de acervos no tempo presente é quanto à serventia que as tecnologias da informação carregam. É evidente que a automação de procedimentos documentários, assim como a constituição de catálogos em linha, são aparatos modernos de relevância. Todavia, não existe um elixir para solução dos problemas no campo da informação. Logo:

Como sabemos, o aumento exponencial da literatura por um lado e a diversidade de de-
mandas de informação por outro, incentivou e, até mesmo, provocou ao longo do tempo
o desenvolvimento de estudos e pesquisas no campo da organização do conhecimento
e da representação da informação. Instrumentos, métodos e técnicas de tratamento da
informação se proliferaram. Atualmente, com a introdução das novas tecnologias de
comunicação e informação, o problema do tratamento da informação, em sua essência
continua o mesmo. O que passa a ser diferente são as novas dimensões das atividades
de coleta, arquivamento, busca e acesso à informação/conhecimento. Continuam a ter
especial interesse o desenvolvimento de instrumentos, métodos e técnicas direcionadas
a solucionar os aspectos cognitivos, operacionais e práticos de tratamento da informa-
ção. (SOUZA, 2000, p. 3)

Como supracitado (com a licença do jargão burocrático), o que há de novo são as novas esferas de aplicação das atividades típicas da Documentação. A ação biblioteconômica não é suprimida, mas sim redimensionada nas suas operações para a constituição de acervos e repositórios, com os desafios inerentes aos diálogos transdisciplinares, como da História, da Ciência da Computação e da própria Documentação.

As mudanças de suporte na inscrição da informação, do físico para o eletrônico, geraram grandes transformações no dispor do conhecimento. Se antes, a visita de pesquisadores aos locais próprios de saber e fazer científico era necessária, hoje não mais. Todavia, o excesso de fluidez informacional, somada aos diversos suportes eletrônicos e a obsolescência pela rapidez da mudança da matriz tecnológica, se tornaram um desafio tanto na recuperação da informação pelos pesquisadores, como para os profissionais da informação.

Outro elemento a ser problematizado está na fidedignidade da informação disposta aos cientistas. Um fenômeno recente e muito abordado são as fake news que não apenas tem um grande poder de influenciar, como criam um grau de incerteza na tomada de decisões, criando ruído e instabilidade na disseminação da comunicação e informação em sociedade.

De fato, este universo tecnológico-digital em que estamos inseridos ainda é muito recente. Discussões se fazem necessárias para uma exploração melhor do contexto atual. Assim:

Ainda se faz importante mencionar que esta discussão sobre a chamada Era Digital ainda é recente. Isto porque novos modelos informacionais foram criados com o objetivo de facilitar a comunicação humana e a velocidade com que se desenvolvem as tecnologias de informação e comunicação - TIC. Todavia, a dinâmica não acompanha os trabalhos de reflexão. Logo, o digital encontra-se no início de sua trajetória. (MELLO, 2017b, p. 39)

Um desafio da fronteira do conhecimento no âmbito da organização de coleções é a contemplação dos retratados na disposição dos acervos. Ou seja, qual seria a organização mais adequada a partir de uma postura epistemográfica (MELLO, 2017a) e por um exercício de pluralismo ético (GUTIÉRREZ, 2006)? Somente com a incorporação das massas excluídas do processo decisório informacional é que se terá uma maior amplitude das possibilidades dos acervos em repositórios públicos e um melhor entendimento das atividades desempenhadas por técnicos e cientistas. 


\section{Considerações quase finais (ou provocações alhures?)}

Este breve ensaio questionou alguns limiares e entendimentos não apenas do fazer científico, mas também da constituição de unidades de informação, como bibliotecas, dispostos em espaços privilegiados da ciência. As denominadas por mim como provocações alhures foi um meio de chamar a atenção para o fato de que a organização do conhecimento é um aprofundamento democrático e dialógico com os diversos estratos de nossa sociedade.

Outro ponto de destaque é a organização das coleções: não é possível indicar ou sugerir que exista um tipo organizacional ou de classificação mais eficaz ou correto. Caberá a cada um de nós definirmos as melhores estratégias na formação de quaisquer coleções. Esta problematização me faz lembrar uma famosa lei da Biblioteconomia - a cada livro o seu leitor - elaborada pelo indiano Shiyali Ramamrita Ranganathan, baluarte da Biblioteconomia moderna.

Da mesma maneira, para cada cientista a sua organização e classificação do conhecimento. Essas reflexões são provocações de como instituições públicas se arvoram de um savoir-faire numa dinâmica entre Estado, sociedade e seus servidores detentores de um material que poderá servir para significar e explicar determinadas circunstâncias históricas. À luz do sinal eletrônico, jovens espalhados pelas periferias do mundo se tornam pensadores e organizadores de coleções em seus tablets e smartphones, processo este que não respeita os limites territoriais e assume uma característica transnacional.

À guisa de conclusão, um posicionamento político que se deve adotar como uma âncora civilizatória-informacional acerca dos repositórios públicos é o acesso irrestrito aos acervos. Ou seja, instituições públicas financiadas pela sociedade precisam estar abertas e disponíveis para qualquer um que queira acesso a informação. Conforme minha trajetória política e acadêmica confio plenamente que somente com a participação ativa da sociedade civil nas instituições podemos justificar os investimentos efetuados em repositórios do Estado brasileiro.

\section{REFERÊNCIAS}

GUTIÉRREZ, Antonio García. Cientificamente favelados: uma visão crítica do conhecimento a partir da epistemografia. Transinformação, Campinas, v. 18, n. 2, p. 103-112, maio/ago, 2006.

LANGRIDGE, Derek. Classificação: abordagem para estudante de Biblioteconomia. Rio de Janeiro: Interciência, 1977.

MACHADO, Elisa Campos; ELIAS JUNIOR, Alberto Calil; ACHILLES, Daniele. A biblioteca pública no espaço público: estratégias de mobilização cultural e atuação sócio-política do bibliotecário. Perspectivas em Ciência da Informação, v. 14, número especial, p. 115-127, out./dez. 2014.

MELLO, Rodrigo Piquet Saboia de. A ação infocomunicacional e a atuação de Mário Juruna para a emancipação política dos povos indígenas. In: VII SEMINÁRIO INTERNACIONAL DE PESQUISAS EM MÍDIA E COTIDIANO - MEDIATIZAÇÃO E SOCIEDADE CONECTADA: ESPAÇOS E MEMÓRIAS DO COTIDIANO, 7., 2018, Niterói. Anais [...]. Niterói: Universidade Federal Fluminense, 2018, p. 816-827.

MELLO, Rodrigo Piquet Saboia de. Alguns apontamentos sobre epistemografia, informação e indigenismo. Revista Conhecimento em Ação, v. 2, n. 2, p. 93-107, jul./dez. 2017a.

MELLO, Rodrigo Piquet Saboia de. A Biblioteca Marechal Rondon e a disseminação de informações de natureza etnológica. Revista Bibliomar, São Luís, v. 16, n. 2, p. 29-43, jul./dez. 2017b.

MELLO, Rodrigo Piquet Saboia de. O fenômeno informacional indígena na contemporaneidade. 2019. 312 f. Tese (Doutorado em Ciência da Informação) - Instituto Brasileiro de Informação em Ciência e Tecnologia, Universidade Federal do Rio de Janeiro, Rio de Janeiro, 2019.

PIEDADE, Maria Antonietta Requião. Introdução à teoria da classificação. Rio de Janeiro: Interciência, 1977.

PRADO, Geraldo Moreira. A biblioteca comunitária como agente de inclusão/ integração do cidadão na sociedade da informação. Inclusão Social, Brasília, DF, v. 3, n. 2, p.143-149, jan./jun., 2010. 
SOUZA, Rosali Fernandez de. A classificação como interface da internet. DataGramaZero: Revista de Ciência da Informação, Rio de Janeiro, v. 2, n. 2, p. 1-6, ago. 2000.

WEITZEL, Simone da Rocha. O desenvolvimento de coleções e a organização do conhecimento: suas origens e desafios. Perspectivas em Ciência da Informação, Belo Horizonte, v. 7, n. 1, p. 61-67, 2002.

WEITZEL, Simone da Rocha. Desenvolvimento de coleções: origem dos fundamentos contemporâneos. Transinformação, Campinas, v. 24, n. 3, p. 179-190, set./dez. 2012. 